\title{
Advances and challenges for sustainable ecosystems
}

\section{A. Arunagiri ${ }^{1}$ - M. Perumalsamy ${ }^{1} \cdot$ T. Sivasankar ${ }^{1} \cdot$ P. Sivashanmugam ${ }^{1} \cdot$ Suranani Srinath $^{2}$}

Published online: 18 March 2020

(C) Springer-Verlag GmbH Germany, part of Springer Nature 2020

Developments with respect to sustainable ecosystem has been the topic of importance in the recent years as industrialization had affected the environment and society in an appreciable way. Sustainable ecosystems have direct implications on environment, safety, economic, and society of a country (Mangili and Prata 2020). Life cycle assessment is one major tool that were widely used by industries to assess the sustainability of the processes which provides complete details starting from the environmental impact assessment, raw materials, production, distribution, techno-economic, environmental management, etc. Sustainable indicators and process simulation could be used suitable to obtain sustainability of an industry. Another major issue that concerns the world is the demand of fresh water. Although seawater desalination has been proved to be effective, it too possess drawbacks such as brine water disposal and indirect contribution to greenhouse gas emission effects. Electrodialysis with bipolar membranes is one technology that could treat the brine water discharged from seawater reverse osmosis process (Herrero-Gonzalez et al. 2020). Generating value added products from waste biomass would reduce the solid waste disposal issues at the same time would generate revenue and offer employment improving societal economic crisis (Joglekar et al. 2019). Wang et al. (2018) had shown that nonvolatile memory device can be prepared from biomaterials which may come in a large way sooner replacing the existing electronic devices that had

Responsible editor: Philippe Garrigues

P. Sivashanmugam

psiva@nitt.edu

1 Department of Chemical Engineering, National Institute of Technology, Tiruchirappalli 620015, India

2 Department of Chemical Engineering, National Institute of Technology, Warangal 506004, India led to huge e-waste generation. Another important aspect requiring sustainability is water/wastewater treatment wherein by establishing sustainable scenario measurable reduction in energy consumption and construction a composting unit would also reduce the pollution levels (Alizadeh et al. 2020).

This special of the Environmental Science and Pollution Research contains selected papers presented in the International conference on Advances and Challenges for Sustainable Ecosystems 2018 (ICACSE 2018) organized by the Department of Chemical Engineering, National Institute of Technology, Tiruchirappalli, India, from 6 to 8 December 2018. The conference was conducted with the theme "Exploring the challenges and opportunities for sustainable ecosystem" keeping in mind of the concept of ecoefficiency defined by World Business Council for Sustainable Development (WBCSD 2006) to create awareness and share the knowledge among the researchers. Based on this theme, conference had aimed to explore the advances on design and operation of chemical plants, development of advanced/novel functional materials and processes, modeling etc. along with focus on interdisciplinary areas. The topics of the papers were chosen with societal focus and conservation of ecosystems. This event had created immense opportunity for young scholars/researchers to interact with experienced delegates and utilized their expertise in the fields of chemical engineering, energy and environmental engineering for sustainable ecosystem.

The conference had attracted as many as 235 papers of which after preliminary scrutiny, 184 papers were accepted for oral presentation and 50 for poster presentation. This conference was conducted in 12 sessions, namely process modeling and simulation, environmental engineering, separation processes, bioenergy, wastewater treatment, nanotechnology, reaction engineering, process control and optimization, energy engineering, transfer operations, materials engineering, and process intensification. The eminent speakers have stressed on the few aspects for the future of sustainable environment, namely, 
conversion of biomass of all sorts into value added chemicals which include HMF, levulinic acid, GVL, acrolein, epichlorohydrin, glycerol carbonate, glycidol, and chemicals based on $\mathrm{CO}_{2}$ will be the major sources of material and energy production; preparation of renewable transportation fuels from biomass for example, sweet sorghum as an ideal food-cum-bioenergy crop to produce food grains as well as bioethanol/algal oil-based biodiesel/highly valuable process by products like amino acids and polyunsaturated fatty acids; tackling municipal solid waste generation of 2.01 billion which was expected to reach 27 billion tonnes in 2050, and its management especially in the developing nations has become a great challenge due to steep rise in consumption and intensity. To have a sustainable waste management system, the functioning of four drivers (i.e., human, economic, environment, and institutional drivers) has proven to be vital; sustainable hydrate energy technologies has been seen as a future energy resource for innovative applications like carbon capture and seawater desalination.

High-quality research papers emphasizing new developments in pollution control were selected and allowed to upload in the journal portal for the special issue in the journal Environmental Science and Pollution Research. Accepted paper after completion of regress reviewing process is published in this special issue.

The organizers of the ICACSE 2018 would like to thank the Chief Editor and the team of this esteemed journal for supporting us to publish high-quality manuscript emerged out of this conference. Also, we would like to thank all the researchers who have shared their research work in our conference.

\section{References}

Alizadeh S, Zafari-koloukhi H, Rostami F, Rouhbakhsh M, Avami A (2020) The eco-efficiency assessment of wastewater treatment plants in the city of Mashhad using emergy and life cycle analyses. Journal of Cleaner Production 249:119327-119340

Herrero-Gonzalez M, Admon N, Dominguez-Ramos A, Ibañe R, Wolfson A, Irabien A (2020) Environmental sustainability assessment of seawater reverse osmosis brine valorization by means of electrodialysis with bipolar membranes. Environ Sci Pollut Res 27:1256-1266

Joglekar SN, Darwai V, Mandavgane SA, Kulkarni BD (2019) A methodology of evaluating sustainability index of a biomass processing enterprise: a case study of native cow dung-urine biorefinery. Environ Sci Pollut Res:1-14. https://doi.org/10.1007/s11356-019-06309-1

Mangili PV, Prata DM (2020) Preliminary design of sustainable industrial process alternatives based on eco-efficiency approaches: the maleic anhydride case study. Chem Eng Sci 212:115313-115340
Wang X, Tian S, Sun B, Li X, Guo B, Zeng Y, Li B, Luo W (2018) From natural biomaterials to environment-friendly and sustainable nonvolatile memory device. Chem Phys 513:7-12

World Business Council for Sustainable Development, 2006. Eco-efficiency. Learning module

Publisher's note Springer Nature remains neutral with regard to jurisdictional claims in published maps and institutional affiliations.

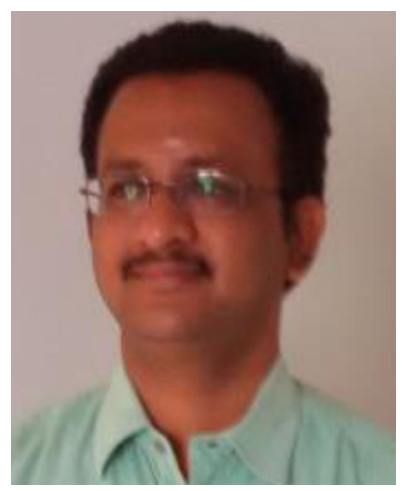

Dr. Appusamy Arunagiri is working as an associate professor in the Department of Chemical Engineering, National Institute of Technology Tiruchirappalli, India, since May 2006. He had received his undergraduate degree in Chemical Engineering from CIT Coimbatore and postgraduate degree from NIT Tiruchirappalli. He had joined as teaching research associate at A.C. College of Technology, Anna University, Chennai, in 2001 and completed his Ph.D. in "Concurrent two phase upflow through packed bed" in 2006. His areas of interest are mainly in transfer operations and study on hydrodynamics in different contactors, surfactant-based separations, bioethanol from vegetable waste, and membrane-assisted mass and energy exchangers. He had published more than 40 international journals. He had guided several M.Tech. and $3 \mathrm{Ph} . \mathrm{D}$. research projects.

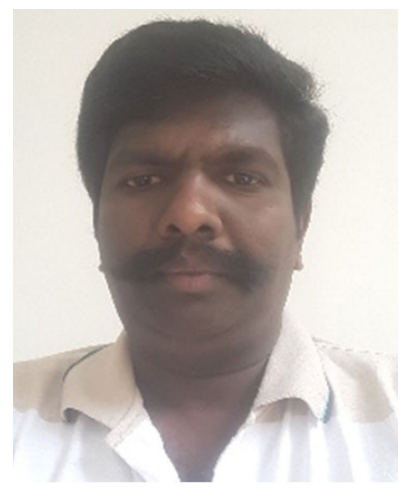

Dr. Muthiah Perumalsamy is an associate professor in the Department of Chemical Engineering at National Institute of Technology, Tiruchirappalli, from 2006 onwards. He has obtained his doctoral degree from A.C.Tech, Anna University, Chennai. He is a recipient of DST Young scientist award during 2010. He has visited University of Iowa, USA, for two months as a visiting scientist and carried out research work on separation and purification of Caffeine Dehydrogenase in Pseudomonas sp. Strain CBB1. He has published more than 60 International papers in reputed journals and conference proceedings. His field of interest includes separation of proteins using aqueous two phase system, computational fluid dynamics, biofuels, and wastewater treatment. 


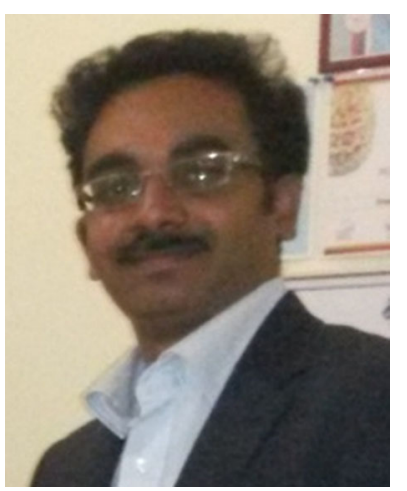

Dr. Thirugnanasambandam Sivasankar is working as an associate professor in the Department of Chemical Engineering at National Institute of Technology Tiruchirappalli. He had graduated from the University of Madras in Chemical Engineering and obtained his postgraduate from Vellore Institute of Technology in Environmental Engineering. Subsequently, he had obtained his Ph.D. from the Department of Chemical Engineering, Indian Institute of Technology Guwahati.

His research areas are environmental pollution control, wastewater treatment, advanced oxidation technologies, sonochemical wastewater treatment, nanoparticle synthesis, and biodiesel synthesis processes. He had published several international journals, international conference presentations, and book chapters. He was awarded with a research project from Department of Science and Technology under DST-SERC Fast Track Project for Young Scientist in 2009 and had completed a Ministry of Environment and Forest sponsored research project in 2014. He is a constant reviewer for several international journals. He has been awarded "IEI Young Engineers Award 2013-2014 under Chemical Engineering Division" by the Institution of Engineers (India). To his credit, he has guided three Ph.D.'s and guiding several Ph.D.'s.

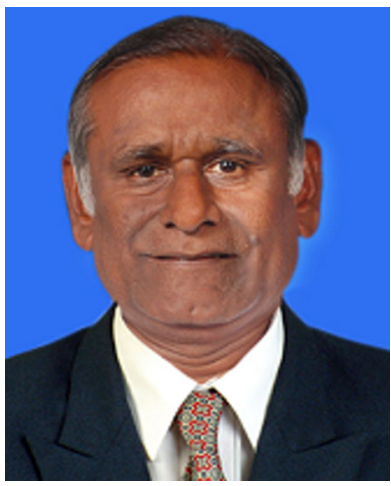

Dr. Palani Sivashanmugam with Ph.D. in Chemical Engineering is working as professor (HAG), in the Department of Chemical Engineering, National Institute of Technology, Tiruchirappalli, 620015, India, from 2007 to date and his research areas are heat transfer enhancement using nanofluids, bioenvironmental engineering, and chemical process engineering. He has written a book on Basics of Environmental Engineering. He is the recipient of the Best teacher award in the year 2007 and Distinguished Alumni award in the year 2014. He has many sponsored research projects and published around 150 research papers in international journals, national journals, and national and international conferences.

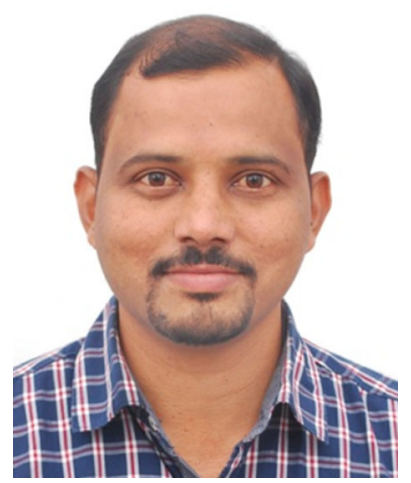

Dr. Srinath Suranani is currently working as an associate professor in the Department of Chemical Engineering, National Institute of Technology Warangal. He obtained his Ph.D in Chemical Engineering from NIT Warangal, India. He is actively involved in teaching, research, and consultancy for the past twenty years. His main areas of scientific research are thermal conversion of solid waste, biofuels, catalysis, process intensification, and process modeling and simulation. He has completed five R\&D projects sponsored by different funding agencies like MHRD, ISRO, DRDO, and IGM. Besides R\&D projects, he has also involved in consultancy projects on simulation of process plants and awarded with one Indian patent. He has also conducted short-term programs including prestigious GIAN courses for faculty, students, and industry people at NIT Warangal and also in different colleges. He has published over 50 research articles in reputed journals, conference proceedings, and book chapters. 